\title{
Luminescent and Dosimetric Properties of Thin Nanostructured Layers of Aluminum Oxide Obtained Using Evaporation of a Target by a Pulsed Electron Beam
}

\author{
A. I. Surdo*, I. I. Milman, M. I. Vlasov, V. G. Il'ves, and S. Yu. Sokovnin \\ Institute of Industrial Ecology, Ural Branch, Russian Academy of Sciences, Yekaterinburg, 620219 Russia \\ Ural Federal University, Yekaterinburg, 620002 Russia \\ Institute of Electrophysics, Ural Branch, Russian Academy of Sciences, Yekaterinburg, 620016 Russia \\ *e-mail:surdo@ecko.uran.ru \\ Received July 16, 2012
}

\begin{abstract}
Results of a study of optically and thermally stimulated luminescence (OSL and TL) of thin nanostructured aluminum oxide coatings obtained with evaporation of the target by a pulsed electron beam and deposited on quartz glass, $\mathrm{Al}$, steel, $\mathrm{Cu}$, Ta, and graphite wafers are presented. It follows from data of X-ray phase analysis that the obtained $\mathrm{Al}_{2} \mathrm{O}_{3}$ layers have an amorphous nanocrystal structure with different contents of the $\gamma$ phase depending on the geometry of the wafer location on evaporation and annealing temperature of the samples. It is established that the material of the wafer and the ratio of the amorphous and $\gamma$ phase in $\mathrm{Al}_{2} \mathrm{O}_{3}$ layers affect the yields of OSL and TL. Annealing at up to $970 \mathrm{~K}$ results in an increase of $\gamma$-phase concentration and OSL and TL responses. It was found that the yields of OSL and TL for the most emission-effective coating samples are comparable with those for the detectors on the basis of anion-defective corundum. The dose-dependence for $\beta$ radiation, which was linear in the range 20-5000 $\mathrm{mGy}$, was investigated.
\end{abstract}

DOI: $10.1134 / \mathrm{S} 1063785013010252$

The increased application of different forms of aluminum oxide in luminescence dosimetry-monocrystal (detectors TLD-500K or $\alpha-\mathrm{Al}_{2} \mathrm{O}_{3}: \mathrm{C}[1]$ ), powder (Luxel on the basis of $\alpha-\mathrm{Al}_{2} \mathrm{O}_{3}: \mathrm{C}[1]$ ), and thin layer (on the basis of nanopowders of $\mathrm{Al}_{2} \mathrm{O}_{3}$ and nanostructures [2, 3]) - is spurring on a search for novel technologies of production of materials on its basis with high sensitivity and selectivity for various types of ionizing radiation.

According to the NRB-99/2009 requirements of radiation safety, thin layer detectors are necessary for correct determination of the input of $\beta$ radiation and the soft component $(\leq 30 \mathrm{keV})$ of photonic radiation into an equivalent dose of the mixed $\beta$-photonic radiation fields. The mass thickness of its active layer should be $5 \mathrm{mg} / \mathrm{cm}^{2}$, which corresponds to the average thickness of the most radiation-sensitive basal-skin layer and equator of an eye lens [4]. Estimation of the linear thickness of the sensitive layer of the detector shows that, for the most available luminescence detector materials ( $\mathrm{LiF}, \mathrm{Al}_{2} \mathrm{O}_{3}, \mathrm{BeO}, \mathrm{MgO}$ ), its value is in the range $10-70 \mu \mathrm{m}$ and depends on their density. The range of the registered equivalent doses for $\beta$ radiation, for example, should be $1-5000 \mathrm{mSv}$. Hence, two opposite requirements are imposed upon the development of thin-layer detectors: high luminescence yield and low thickness of the active layer. It is essential to mention in this connection that examples of applica- tion of thin layer detectors obtained from $\mathrm{LiF}: \mathrm{Mg}, \mathrm{Ti}$ [5], $\alpha-\mathrm{Al}_{2} \mathrm{O}_{3}: \mathrm{C}$ [1], and $\mathrm{MgB}_{4} \mathrm{O}_{7}$ [4] powders with thickness of $100-300 \mu \mathrm{m}$ exist in skin dosimetry, which do not ensure compliance with the requirements of NRB-99/2009.

Therefore, the purpose of this study is investigation of the luminescence and dosimetric properties of thin nanostructured layers of aluminum oxide obtained using a novel technology based on evaporation of a target with a pulse electron beam (ETPEB).

Nanostructured layers (coatings) of aluminum oxide with a size of $7 \times 7 \mathrm{~mm}$ and average thickness of $20 \mu \mathrm{m}$ deposited with ETPEB on flat Al, steel, $\mathrm{Cu}$, Ta, graphite, and quartz glass wafer with a thickness of $\sim 0.2-0.5 \mathrm{~mm}$ were used as the objects of the study. $\mathrm{Al}_{2} \mathrm{O}_{3}$ nanoparticle coatings with a range of coherent scattering of 50-70 nm were applied under vacuum (residual pressure $4 \mathrm{~Pa}$ ) using evaporation of a target made from highly purified $\alpha-\mathrm{Al}_{2} \mathrm{O}_{3}$ powder (IAM (United States)) with a NANOBIM-2 instrument at an electron energy of $40 \mathrm{keV}$, pulse duration of $100 \mu \mathrm{s}$, frequency of $200 \mathrm{~Hz}$, and pulse energy density of $0.56 \mathrm{~J} / \mathrm{mm}^{2}$ for $5 \mathrm{~min}[6]$. X-ray phase analysis (XPA) of the obtained samples was conducted with an XRD 7000 diffractometer (Shimadzu (Japan)) using $\mathrm{Cu} K_{\alpha}$ radiation. TLD-500K moderate sensitivity detectors on the basis of monocrystal anion-defective corun- 


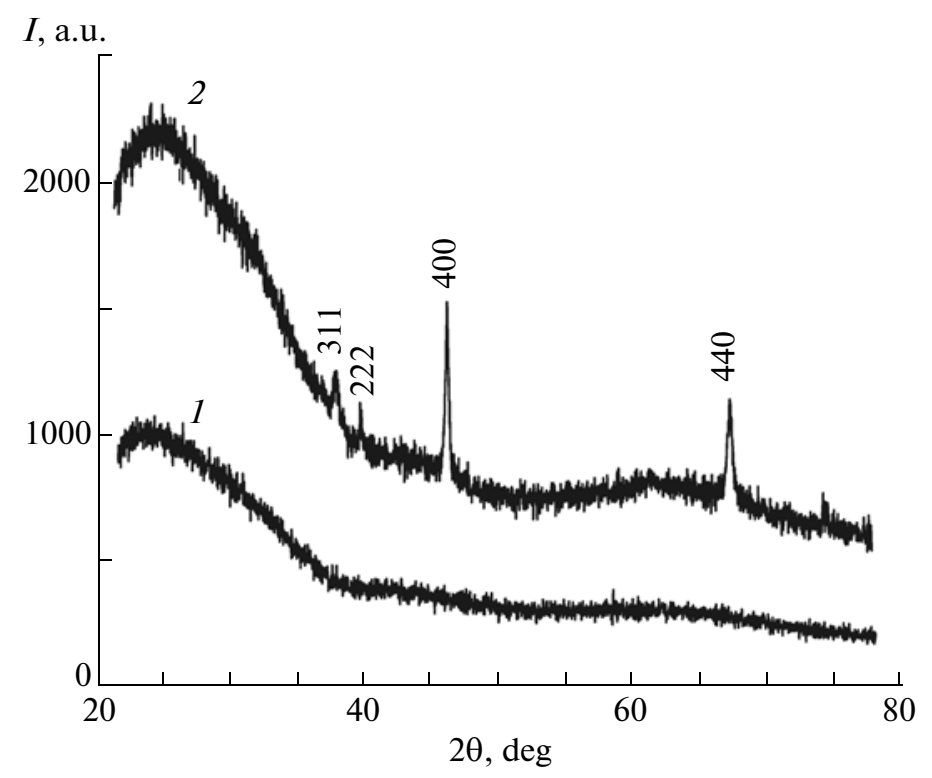

Fig. 1. Diffractograms of nanostructured $\mathrm{Al}_{2} \mathrm{O}_{3}$ coating samples of (1) type 1 and (2) type 2 differing in luminescence responses.

dum $\left(\alpha-\mathrm{Al}_{2} \mathrm{O}_{3}\right)$ were used for comparative studies of luminescent and dosimetric properties.

Decay curves of optically stimulated luminescence (OSL) and thermoluminescence (TL) curves and spectral composition of TL were investigated with an automatic instrument developed for this purpose [7]. Samples were excited with $\beta$ radiation of a ${ }^{90} \mathrm{Sr} /{ }^{90} \mathrm{Y}$ source $(P=0.5 \mathrm{mGy} / \mathrm{s})$ and $\mathrm{X}$-ray radiation (Rh-anode, $U=30 \mathrm{kV}, I=1-40 \mu \mathrm{A}$ ). TL and OSL signals were recorded with FEU-106 and FEU-142 photomultipliers, including with the use of an MSD-2 monochromator. A mode of continuous stimulation was used with the measurements of OSL decay curves. Blue LEDs $\left(\lambda_{\max }=470 \mathrm{~nm}\right)$ such as SDK-S469-5-10 were the sources of stimulation. An UFS-2 filter was used to separate the stimulating radiation from the OSL signal.

Preliminary studies of OSL and TL of 12 samples prepared in the same cycle showed that some of them exhibit significant luminescence yield. Two sets of samples with minimum (type 1) and maximum (type 2) OSL and TL responses were selected with this in mind. A comparison of OSL and TL properties and the location of the wafer during ETPEB allowed it to be established that the OSL and TL yields depended on the geometry of sample locations relative to the plasma flame of the evaporated material, with all other factors (thickness of coating, its homogeneity) being the same. It follows from XPA data (Fig. 1) that, in both types of samples, the amorphous component predominates, which manifests itself on diffractograms as a smooth curve of diffusive scattering similar to the type 1 sample with low response (curve 1 ). Up to $10-$ $20 \%$ of the $\gamma$ phase was observed for the type 2 samples with an increased OSL and TL (curve 2), the input of which was assessed by the intensity of characteristic peaks at 400 and $440 \mathrm{~nm}$ (card 00-029-0063 of the PDF-2 database) using the XRD Crystallinity program.

Typical OSL decay curves for the type 1 and 2 samples at X-ray radiation dose $D_{x}=4.0 \mathrm{~Gy}$ are presented in Fig. 2a. It can be seen that the difference in OSL response (curves 1 and 2) is no less than two orders of magnitude. Moreover, normalized for the mass of sensitive layer OSL yields for the type 2 sample and TLD$500 \mathrm{~K}$ detector with average sensitivity are comparable (curves 1 and 3).

Analysis of the obtained data allows it to be suggested that the luminescence properties of the investigated nanostructured $\mathrm{Al}_{2} \mathrm{O}_{3}$ layers are related to the $\gamma$-phase content. Considering that the $\gamma$-phase transition occurs at $T=970-1020 \mathrm{~K}$ [8], a significant increase of OSL yield should be expected with an increase of the sample annealing temperatures. Separate OSL decay curves for the type 2 samples and total changes of the OSL integral yield $S_{\mathrm{OSL}}$ (light sum) in relation to temperature of isochronic annealing $T_{A}$ up to $970 \mathrm{~K}$ for $10 \mathrm{~min}$ in the air are presented in Fig. 2b and the inset. It can be seen that the suggestion that has been made is confirmed: the OSL yield increases by no less than 2- to 2.5-fold after more complete transition of the investigated nanostructured $\mathrm{Al}_{2} \mathrm{O}_{3}$ layers to the $\gamma$ phase. The further temperature increase $\left(T_{A}>1000 \mathrm{~K}\right)$ resulted in separation of the layer from the quartz glass wafer. Nevertheless, annealing at elevated temperatures is of interest, because it will facilitate $\gamma$-phase transition to more ordered and densely packed crystal forms: $\delta(1250 \mathrm{~K}) \longrightarrow \theta(1320 \mathrm{~K}) \longrightarrow$ $\alpha(1420 \mathrm{~K})[8]$; and anion-defective modification of $\alpha-\mathrm{Al}_{2} \mathrm{O}_{3}$ offers one of the highest TL and OSL yields [1]. 


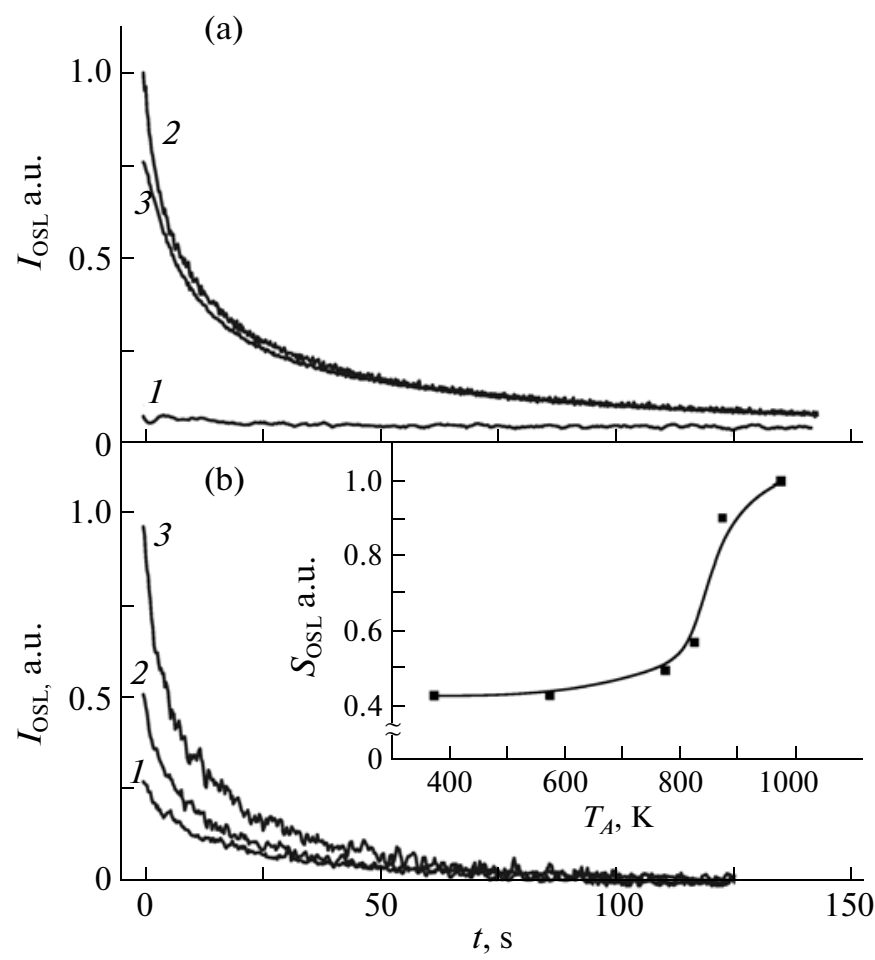

Fig. 2. (a) OSL decay curves of (1) type 1 and (2) type 2 samples and (3) TLD-500 K detector at $T=295 \mathrm{~K}$ and $D_{x}=4.04 \mathrm{~Gy}$; (b) OSL curves of the type 2 sample recorded at $T=295 \mathrm{~K}$ and $D_{x}=0.8 \mathrm{~Gy}$ after isochronic annealing at (1) $T_{A 1}=570 \mathrm{~K}$, (2) $T_{A 2}=830 \mathrm{~K}$, and (3) $T_{A 3}=970 \mathrm{~K}$ and $S_{\mathrm{OSL}}\left(T_{A}\right)$ dependence (inset).

Further efforts were directed toward investigation of TL properties of type 2 samples annealed at $1420 \mathrm{~K}$; materials with good thermal conductivity, including high melting, were selected as wafers. TL curves for the coating samples deposited onto $\mathrm{Al}$, steel, $\mathrm{Cu}, \mathrm{Ta}$, and graphite (curves 1-5) at the heating rate $2 \mathrm{~K} / \mathrm{s}$ are presented in Fig. 3a together with the TL spectral composition presented in the inset. All curves display one complex peak of the same shape with a maximum at $450-460 \mathrm{~K}$ and a shoulder in the range $365-370 \mathrm{~K}$. One luminescence band with a maximum at $3.8 \mathrm{eV}$ and half-width of $0.6 \mathrm{eV}$ is observed in the TL spectrum (Fig. 3a, inset), which is close to the luminescence of the $\mathrm{F}^{+}$center in $\alpha-\mathrm{Al}_{2} \mathrm{O}_{3}$ by its parameters [9, $10]$. The half-width of the TL peak at $455-460 \mathrm{~K}$ is 2.5- to 3-fold greater than that of a TLD-500 K detector on the basis of anion-defective $\alpha-\mathrm{Al}_{2} \mathrm{O}_{3}$ (curve 6). The sample on an $\mathrm{Al}$ wafer exhibits the highest TL yield (curve 1); that on graphite (curve 5) exhibits the lowest. The sample on the steel wafer most suitable for annealing to $1420 \mathrm{~K}$ according to its combined physico-chemical properties (melting temperature, adhesion characteristics, linear coefficient of thermal expansion) provides a rather high TL response. Moreover, it should be mentioned that the TL yields normalized for the mass of sensitive volume are compara-

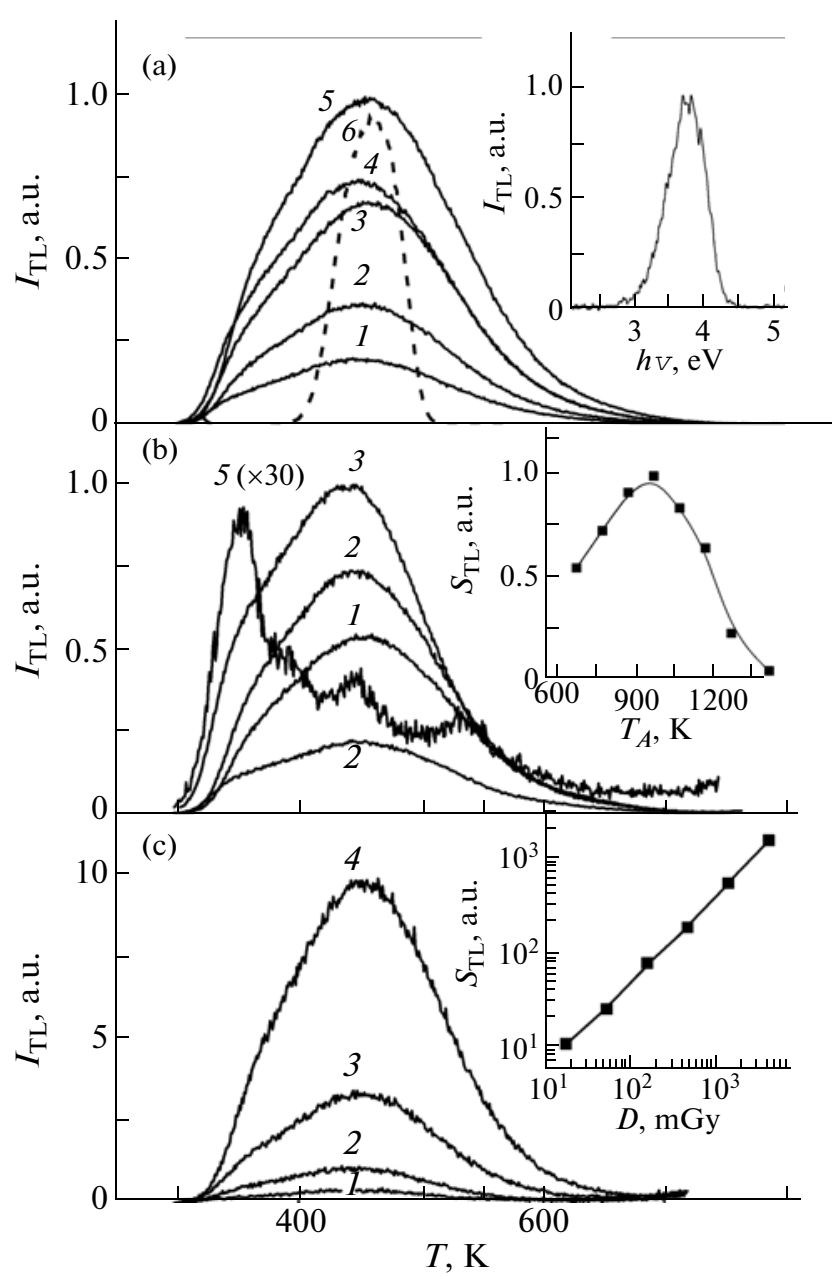

Fig. 3. (a) TL curves of the coating samples on (1) Al, (2) steel, (3) $\mathrm{Cu}$, (4) Ta, and (5) graphite wafers and (6) TLD-500 K detector at $T=295 \mathrm{~K}$ and $D_{x}=4.0 \mathrm{~Gy}$; spectral composition of TL of coatings is presented in the inset; (b) TL curves of the coating on the steel wafer recorded at $D_{x}=4.0 \mathrm{~Gy}$ after isochronic annealing at (1) $T_{A 1}=670 \mathrm{~K}$, (2) $T_{A 2}=770 \mathrm{~K}$, (3) $T_{A 3}=970 \mathrm{~K}$, and (4) $T_{A 4}=1270 \mathrm{~K}$ and $S_{\mathrm{TL}}\left(T_{A}\right)$ dependence (in the inset); (c) separate curves of TL recorded at $\beta$-radiation doses: (1) 160 , (2) 480, (3) 1440 , and (4) $4320 \mathrm{mGy}$ and $S_{\mathrm{TL}}$ (D) dependence (inset).

ble for TLD-500 $\mathrm{K}$ and samples on aluminum and steel wafers.

The dependence of separate TL curves for the sample on a steel wafer on the temperature of isochronic annealing in the range $770-1420 \mathrm{~K}$ is presented in Fig. $3 \mathrm{~b}$ (curves $1-5$ ) together with the changes of the integral yield of TL $S_{\mathrm{TL}}$ in the inset. An approximately twofold increase of the TL yield occurs with the increase of annealing temperature to $970 \mathrm{~K}$, as in the case of similar dependencies obtained for OSL investigation (Fig. 2b). Further temperature increase to $1420 \mathrm{~K}$ results in significant drop of TL yield. The TL curve undergoes significant transformations after $1420 \mathrm{~K}$ annealing: three low-intensity narrow peaks at 
350,450 , and $540 \mathrm{~K}$ are observed. One of the main reasons for the observed decrease of TL yield and radical transformation of the TL curve after annealing at $1420 \mathrm{~K}$ may be restoration of stoichiometric composition in the annealed sample of $\mathrm{Al}_{2} \mathrm{O}_{3}$. Transformation of the nanostructured $\mathrm{Al}_{2} \mathrm{O}_{3}$ to the $\alpha$ phase at $1420 \mathrm{~K}$ cannot be the main reason for the drop in luminescence response, as it is precisely anion-defective $\alpha-\mathrm{Al}_{2} \mathrm{O}_{3}$ that possesses a uniquely high TL yield.

Dose dependencies of the obtained material were investigated on irradiation with $\beta$ particles of the ${ }^{90} \mathrm{Sr} /{ }^{90} \mathrm{Y}$ source to estimate their functional capabilities. TL curves at different doses of $\beta$ irradiation and dose-dependencies of the TL yield $S_{\mathrm{TL}}$ (D) are shown in Fig. 3c and its inset for a sample on a steel wafer annealed at $750 \mathrm{~K}$. It can be seen that the dependence of $S_{\mathrm{TL}}(\mathrm{D})$ presented in a logarithmic scale is linear in a dose range of 20-5000 mSv and can meet the NRB99/2009 requirements for skin dosimetry. Nevertheless, the lower limit of the dose range can be decreased significantly by developing new technologies for thinlayer generation and by sample annealing at $970 \mathrm{~K}$ (Fig. 3b).

Hence, the presented results attest to the preparation of a novel, promising thin-layer detector material on the basis of nanostructured $\mathrm{Al}_{2} \mathrm{O}_{3}$ for dosimetry of $\beta$ radiation and the soft component $(\leq 30 \mathrm{keV})$ of photonic radiation. The created material offers increased yields of OSL and TL comparable with those for one of the leaders among detectors-TLD-500 K. The potentials of the developed technology of thin-layer deposition using target evaporation with a pulse electron beam are not fully exhausted. Exact doping of the detector material with active ingredients and production of layered and stepwise structures for separation of input of photonic radiation and particles with different penetrating and ionizing abilities is possible with its help.

Acknowledgments. This work was supported in part by the Russian Foundation for Basic Research (project no. 10-08-96045) and the Presidium of the Ural Branch of the Russian Academy of Sciences (projects nos. 12-U-2-032 and 12-2-013-UEMZ).

\section{REFERENCES}

1. E. G. Yukihara and S. W. S. McKeever, Optically Stimulated Luminescence: Fundamentals and Applications (Wiley, Chichester, 2011).

2. M. W. Blaier, L. C. Jacobsohn, S. C. Tornga, O. Ugurlu, B. L. Bennett, E. G. Yukihara, and R. E. Muenchausen, J. Lumin. 130, 825 (2010).

3. J. E. Villarreal-Barajas, L. Escobar-Alarcon, E. Camps, P. R. Gonzalez, and E. Villagran, Superfic. Vacio 13, 126 (2001).

4. Control of Equivalent Doses of Photonic and Beta-Radiation in Skin and Eye Lens: Methodological Instructions (MU 2.6.1.56-2002), Ed. by A. I. Shaks [in Russian].

5. H. Jarvinen, W. G. Gross, C. Soares, S. Vynckier, and K. Weaver, J. ICRU 4 (2), Report No. 72 (2004).

6. V. G. Il'ves, A. I. Medvedev, A. M. Murzakaev, S. Yu. Sokovnin, A. V. Spirina, and M. A. Uimin, Fiz. Khim. Obrab. Mater., No. 2, 18 (2011).

7. I. I. Milman, E. V. Moiseikin, S. V. Nikiforov, S. V. Solov'ev, I. G. Revkov, and E. N. Litovchenko, Phys. Solid State 50, 2076 (2008).

8. R.-S. Zhou and R. L. Snyder, Acta Crystallogr. 47, 617 (1991).

9. B. D. Evans and M. Stapelbroek, Phys. Rev. B. 18, 7089 (1978).

10. A. I. Surdo, Izv. Vyssh. Ucheb. Zaved.: Fiz. 54 (1), 277 (2011).

Translated by A. Brovko 